\section{Information preferences of people living with fibromyalgia - a survey of their information needs and preferences}

\author{
Lubna Daraz, ${ }^{1}$ Joy C. MacDermid, \\ Seanne Wilkins, ' Jane Gibson, ${ }^{2}$ \\ Lynn Shaw ${ }^{3}$
}

1School of Rehabilitation Science, Faculty of Health Sciences, McMaster University, Hamilton, ON; ${ }^{2}$ Knowledge Translation, Institute for Work \& Health, Toronto, ON; ${ }^{3}$ Faculty of Health Sciences, School of Occupational Therapy, University of Western Ontario, London, ON, Canada

\section{Abstract}

A lack of understanding about fibromyalgia and how to live with it may undermine the foundations of self-management and may compromise quality of life. The purpose of this study was to determine the information needs and preferences pertinent to people living with fibromyalgia. A cross-sectional web-based survey was developed based on conceptual and qualitative work informing information needs. Recruitment took place through hospitals, clinics, physicians and fibromyalgia support groups across Canada. Descriptive statistics using SPSS and graphical representations were employed to summarize and represent data. A total of 442 respondents (93\% female, mode age 51-65) participated in the survey. No statistical differences in information needs were found between males and females or education level. Respondents (74\%) frequently searched for information about fibromyalgia using a variety of resources including Internet (91\%), doctors (75\%), support groups (76\%), and people with same condition (87\%). Respondents expressed a strong need for information about symptoms (81\%), implications $(79 \%)$, treatments $(87 \%)$, resources (85\%) and coping (79\%). However, concerns were expressed about the reliability of information and majority (93\%) wanted information to be available online that is provided by healthcare providers or from reputable sources. Internet (48\%), people with similar condition (35\%) and support groups (35\%) were perceived as useful resources for people living with fibromyalgia. Information resources need to be developed on the basis of both content and knowledge of the information needs of the target end-user. Healthcare providers and the Internet are expected to be reliable resources of information.

\section{Introduction}

Fibromyalgia is a common, disabling and controversial chronic disease that has serious consequences on the health and life of people who are living with the illness. ${ }^{1-4}$ In Canada as many as 1.1 to 3.3 percent people are affected by this disabling disease. ${ }^{5,6}$ Fibromyalgia is six times more common in women than in men., This prevalence of fibromyalgia is similar worldwide and the number is growing each year. ${ }^{2}$ Increased awareness and reporting of the condition is at least partially responsible for this increase. - $^{8-10}$

One of the main symptoms of fibromyalgia is extensive and persistent pain..$^{811,12}$ Fibromyalgia symptoms that are not sufficiently manageable lead to substantial disability. ${ }^{13-16}$ There is no specific diagnostic test that identifies fibromyalgia, but there are efforts to introduce new diagnostic guidelines., ${ }^{8,17,18}$ These guidelines can be used as a foundation for understanding the disease and forming recommendations for effective treatments or management strategies.

Many people diagnosed with fibromyalgia stop working due to limitations in work capacity. Researchers who studied work capability of people living with fibromyalgia found that better awareness and use of work adaptations would allow people to be more successful in the labor markets. ${ }^{12,19,20}$ Given the current rates of disability and work loss, efforts to make people with fibromyalgia better prepared to deal with their illness or work capacity might result in substantially lower health and social costs. Schmidt and colleagues reported that in 2003, the healthcare costs in Sweden for people with fibromyalgia and similar conditions were more than $\$ 2$ billon in US dollars annually. ${ }^{4}$ In the USA, the estimated healthcare cost for people living with fibromyalgia is also between $\$ 12-14$ billion dollars each year. ${ }^{21} \mathrm{~A}$ similar depiction can be observed in Canada where many Canadians are also affected by fibromyalgia. ${ }^{6,22}$ A study by White and colleagues in London, Ontario, Canada found that annual costs, medications, and health services use among people living with fibromyalgia were twice that of those without widespread pain. ${ }^{6}$ As a result, the challenges for managing fibromyalgia become a burden for both people living with the illness and the healthcare systems. ${ }^{6,23}$

Qualitative studies that reported the experience of people living with fibromyalgia have identified the complex challenges of managing family life, work conditions, psychological problems and a lack of support from healthcare providers, family members and society. ${ }^{4,20,24-26}$ Unfortunately, much of the research relating to this condition focused on medical aspects of the disease while paying little attention to the information needs and preferences of people
Correspondence: Lubna Daraz, School of Rehabilitation Science, Faculty of Health Sciences, McMaster University, 1400 Main St.West. IAHS - 403, Hamilton, ON L8S4L8 Canada. Tel: +1.647.781.8536.

E-mail: darazl@mcmaster.ca

Key words: fibromyalgia, information needs, Internet, survey, coping, quality of life.

Acknowledgements: this work was supported by a Doctoral Research Award (Frederick Banting and Charles Best Scholarship) from the CIHR; a Strategic Training Fellowship in Rehabilitation Research from the CIHR Musculoskeletal and Arthritis Institute; a S. Leonard Syme Training Fellowship from the Institute for Work \&Health; and a MSK Training Fellowship from the Ontario Rehabilitation Research Advisory Network to Lubna Daraz.

Conflict of interest: the authors report no conflicts of interest.

Received for publication: 27 June 2011.

Accepted for publication: 12 August 2011.

This work is licensed under a Creative Commons Attribution 3.0 License (by-nc 3.0).

(C) Copyright L. Daraz et al., 2011

Licensee PAGEPress, Italy

Rheumatology Reports 2011; 3:e7

doi:10.4081/rr.2011.e7

living with fibromyalgia. ${ }^{1,4,27}$ Previous authors have suggested that a lack of understanding and knowledge of the disease are among the most important factors that contribute to a lower quality of life and inability to manage the illness. ${ }^{1,5}, 18,9,28-31$ As Crooks stated, an important element of negotiating life with a chronic illness, for many, is seeking out information which can be used to come to a greater understanding of one's changed/changing body and possible treatment options. ${ }^{10}$ There is also evidence that interventions that increase people's knowledge, skills and confidence positively affect their well-being. ${ }^{32}$ The Chronic Care Model that was developed by Wagner and collegues $^{27}$ to improve care of chronically ill patients, the developers of the model advocated for knowledge and information as critical components of chronic disease management. ${ }^{27}$ Appropriate information can assist people in managing their illness and making informed decisions about their health. ${ }^{10,32,33}$

Daraz and others studied the experience of information use by women living with fibromyalgia. ${ }^{34}$ Their study findings reported that women received limited information from their healthcare providers and lacked access to quality information about their illness. Despite their fundamental information needs, women 
struggled to find and access appropriate information. They used diverse strategies such as personal capacities, supports through connections with others and new research in overcoming some of the challenges in accessing information. In spite of the challenges, women reported that they were able to draw on accessed information to make changes and to begin to coordinate their lives to live with fibromyalgia. This qualitative study ${ }^{34}$ suggested that information on fibromyalgia does support people living with this health disorder. However, it does not necessarily represent the broad audience of people who might potentially use this information due to the small sample size. Given the expressed importance, it is essential to explore a broader description of these needs before pursuing resource development. Since the suitability of information content and format should be matched to the majority of the target audience, it is worthwhile to define these. Therefore, the purposes of this study were to identify the: i) information needs of people living with fibromyalgia; ii) importance assigned to specific categories of information; iii) ways people find/use information about fibromyalgia; iv) information format preferred by people living with fibromyalgia.

\section{Materials and Methods}

\section{Methodology}

This study was a cross-sectional national survey targeting people living with fibromyalgia.

\section{Survey development}

The content for specific items of the survey were generated from multiple sources including the issues identified by the qualitative study on this topic by Daraz and others and studies of information needs of similar groups of people. $8,13,23,34,35$ The structure and scaling items were selected using established principles $^{36,37}$ and consensus between two lead authors. The wording and structure of the overall survey questionnaire were independently evaluated by each of the authors and iteratively revised for both content and clarity.

The final draft of the survey was pilot tested among participants who were not part of the sampling frame $(n=10)$. This process resulted in further modification /simplification by minor changes to the format of the survey and individual items, clarity of specific items and removal of redundant questions. The final version of the survey was launched using Survey Monkey [http://www.surveymonkey.com/] which is a web-based survey tool that allows participants to complete a survey easily and anonymously using the Internet.
The survey was preceded by an informed consent form and included the following components (in order): i) Information Need, ii) Access to Information, iii) Information Use, iv) Use of Online Information and v) Demographics. The response items were set as a 7 point scale where possible. For example, items regarding importance of content, responses were categorized as very important, important, somewhat important, neutral, somewhat unimportant, unimportant and very unimportant. During analysis, items were collapsed into fewer categories to analyze differences in information needs based on education and gender. We dichotomized the 7-point scale into a 2-point scale (important, not important) based on the response rate.

\section{Survey population}

The following inclusion criteria were used to recruit participants for the survey: i) people (male or female) living with fibromyalgia (employed or not), ii) diagnosed with fibromyalgia at least a year prior to the start of the study and iii) able to communicate in English.

The recruitment strategy used to identify people living with fibromyalgia was implemented by contacting gatekeepers of access points (hospitals, clinics, physicians and support groups) in Canada. Study introductory letters were sent to hospitals notice boards, clinics and physicians providing services to people living with fibromyalgia, chronic pain groups and fibromyalgia support groupsto inform them about the study and request their cooperation in recruitment. An electronic link to the survey was then sent to the gatekeepers who expressed their interest in the study to distribute to their members/patients using their email lists. Both males and females were surveyed to examine whether information needs and preferences varied by gender. The survey was launched on Survey Monkey on February 5, 2010 and closed on March 31, 2010.

The Survey Monkey software generated random numbers that were used as identifiers to allow for confidential responses. The exact number of people who were approached for participation was difficult to estimate since it was done through intermediaries, the accuracy of their e-mail lists was not verifiable and members of support groups were not all registered. As a result, it was not possible to estimate response rate. Further, since responses were anonymized, the recruitment source/site was unknown to the researchers.

\section{Survey analyses}

Routine survey analysis can be performed by Survey Monkey. Data were imported directly into EXCEL spreadsheet and then into SPSS (SPSS - IBM. http://www.spss.com) for more detailed analysis. A coding of open-ended responses (i.e. additional comments) was developed by categorizing responses based on responses received for closed-ended questions. This process continued until all of the responses were coded successfully. To evaluate the difference between two educational groups and genders a statistical test of difference (ChiSquare) was conducted.

Descriptive statistics and graphical representations were employed to summarize and represent data.A power calculation for estimation using 442 respondents assuming a worst case proportion (0.5) and a 95\% confidence interval indicated a margin of error of 0.046 . The power calculation for 442 respondents, $\alpha=.05$, assuming $50 \%$ as one proportion (worst case scenario) indicated that $10 \%$ difference would be detected with $80 \%$ power. In all statistical analyses, a $\mathrm{P}<0.05$ was considered statistically significant.

\section{Results}

Table 1 displays significant demographic characteristics of the sample. About $93 \%$ of the participants were female and $7 \%$ were male. The majority of the participants were Caucasian (96\%) with post-graduate education (87\%) and a significant number (69\%) did not have a job due to fibromyalgia. Most of the respondents (94\%) spoke English fluently enough to participate. The median time since diagnosis was 9 years with a range of $<1-35$ years. About $74 \%$ of the respondents frequently searched for information about fibromyalgia and reported a variety of information needs (Table 2). From the people who provided responses (26\%) to the open-ended (category other) question, $23 \%$ of those reported that they searched for information to be knowledgeable about fibromyalgia, $11 \%$ wanted to

Table 1. Respondents demographic information $(n=442)$.

\begin{tabular}{lr}
\hline Age Category (\%) & \\
18-30 years & 4.2 \\
31-50 years & 41.7 \\
51-65 years & 45.7 \\
Over 65 years & 8.4 \\
Gender ( $\mathrm{n}=442)(\%)$ & \\
$\quad$ Female & 93.3 \\
Male & 6.8 \\
\hline Ethnic Background ( $\mathrm{n}=442)(\%)$ & \\
$\quad$ Caucasian & 95.6 \\
$\quad$ Others & 4.3 \\
Average time since diagnosis (yr) & 9 \\
\hline Employment Status ( $\mathrm{n}=442)(\%)$ & \\
$\quad$ Working & 30.8 \\
$\quad$ Not-working & 69.2 \\
Education ( $\mathrm{n}=442)(\%)$ & \\
$\quad$ High School or less & 12.8 \\
$\quad$ Post-Graduate & 87.2 \\
\hline
\end{tabular}


know more about coping, $20 \%$ wanted to know about treatments, $28 \%$ were not happy with healthcare systems/ professionals and the remainder of the respondents wanted information for family/friends, or to improve their quality of life. A substantial portion ( $80 \%$ or higher) of the respondents felt that it was very important to obtain information about symptoms, management, treatment options and to find someone who can help with their disease (Table 3 ) at the time of diagnosis. In addition, comments reported in the open-ended (category 'other') responses (25\%) included more information about fibromyalgia (25\%), diagnosis (16\%), and concerns about healthcare providers (18\%) and the rest discussed information sources, support groups, medication and diet. There were no differences between those who had post secondary education and those less well-educated with respect to this high level of endorsement (Table 4). Similarly, more than $60 \%$ of the respondents felt that it was important for them to find information about the impacts of the disease on health and life, treatment options, medications, exercise, food, supports and coping after their diagnosis (Table 5). From the people who provided responses (19\%) to the open-ended (category other) question also discussed their frustration about the lack of information from healthcare providers (29\%), the need for more information about fibromyalgia (8\%) and the remainder discussed wanting more information onself-help, quality of life, resources and insurance. There were no differences between males and females with respect to this high level of endorsement (Table 6). People reported variable difficulty in accessing the information they need. Approximately equal numbers reported that accessing information was not difficult (45\%) versus those who had difficulty (43\%). The majority of the respondents (99\%) obtained information online. Furthermore, most (91\%) of the respondents found it easy to access online information and did so frequently - with $84 \%$ doing so at least once per month. They also reported accessing from other sources including doctors (75\%), rheumatologist (58\%), health magazines (61\%), scientific studies (67\%), support groups (76\%), and people with the same condition (87\%). However, other sources that were infrequently accessed were nurses (16\%), occupational therapists (21\%), psychiatrists (31\%) and dieticians/ nutritionists (25\%). Table 7 reports the frequency of use of the sources.

Table 2. Reasons people with fibromyalgia search for information (n-442).

\begin{tabular}{lcccccccc}
\hline Information needs & $\begin{array}{c}\text { Strongly } \\
\text { agree } \\
(\%)\end{array}$ & $\begin{array}{c}\text { Agree } \\
(\%)\end{array}$ & $\begin{array}{c}\text { Somewhat } \\
\text { agree } \\
(\%)\end{array}$ & $\begin{array}{c}\text { Neutral } \\
(\%)\end{array}$ & $\begin{array}{c}\text { Somewhat } \\
\text { disagree }\end{array}$ & $\begin{array}{c}\text { Disagree } \\
(\%)\end{array}$ & $\begin{array}{c}\text { Strongly } \\
\text { disagree } \\
(\%)\end{array}$ & $\begin{array}{c}\text { Total } \\
\text { Respondents }\end{array}$ \\
Learn more about fibromyalgia & 83.1 & 12.9 & 2.3 & 0.5 & 0.2 & 0.5 & 0.5 \\
Help make decisions about health & 82.2 & 14.5 & 1.9 & 0.9 & 0.0 & 0.2 & 0.2 & 427 \\
\hline Learn about new research & 80.0 & 15.5 & 2.1 & 2.1 & 0.0 & 0.0 & 0.2 & 426 \\
Self-manage of health & 69.7 & 20.1 & 5.9 & 2.6 & 0.7 & 0.7 & 0.2 \\
\hline Information for family & 47.5 & 26.1 & 13.3 & 8.8 & 1.7 & 1.2 & 1.4 & 423 \\
Lack of information from healthcare providers & 41.5 & 20.2 & 16.4 & 7.8 & 3.3 & 6.1 & 4.7 & 426 \\
\hline Lack of attention from healthcare providers & 41.3 & 16.2 & 17.3 & 7.6 & 6.2 & 7.4 & 4.0 & 421 \\
Indistinct information from healthcare providers & 33.6 & 21.4 & 14.6 & 12.9 & 4.9 & 7.2 & 5.4 & 425 \\
\hline Embarrassed to ask healthcare providers & 7.3 & 8.7 & 10.9 & 13.0 & 8.7 & 23.6 & 27.7 & 423 \\
\hline
\end{tabular}

Categories exploring the most endorsed responses are bolded.

Table 3. Importance of specific categories of information at the time of diagnosis.

\begin{tabular}{|c|c|c|c|c|c|c|c|c|}
\hline Categories of information & $\begin{array}{c}\text { Very } \\
\text { important } \\
(\%)\end{array}$ & $\begin{array}{c}\text { Important } \\
(\%)\end{array}$ & $\begin{array}{c}\text { Somewhat } \\
\text { important } \\
(\%)\end{array}$ & $\begin{array}{c}\text { Neutral } \\
(\%)\end{array}$ & $\begin{array}{c}\text { Somewhat } \\
\text { unimportant } \\
(\%)\end{array}$ & $\begin{array}{c}\text { Unimportant } \\
\text { (\%) }\end{array}$ & $\begin{array}{c}\text { Very } \\
\text { unimportant } \\
(\%)\end{array}$ & $\begin{array}{l}\text { Total } \\
\text { Respondents } \\
\text { (\%) }\end{array}$ \\
\hline Types of available treatments & 87.1 & 8.9 & 1.2 & 1.6 & 0.2 & 0.2 & 0.7 & 425 \\
\hline Who can help me with my condition & 84.5 & 10.7 & 2.9 & 1.2 & 0.2 & 0.0 & 0.5 & 413 \\
\hline Usual symptoms and how to manage them & 81.0 & 13.4 & 3.1 & 1.6 & 0.5 & 0.0 & 0.5 & 426 \\
\hline Possible health outcomes in the future & 79.1 & 15.3 & 2.8 & 1.9 & 0.0 & 0.0 & 0.9 & 425 \\
\hline Things that I should avoid & 75.5 & 17.2 & 2.6 & 3.5 & 0.2 & 0.2 & 0.7 & 425 \\
\hline Causes of the symptoms & 74.5 & 15.7 & 6.3 & 2.6 & 0.2 & 0.2 & 0.5 & 427 \\
\hline When can I go back to normal activities & 67.5 & 20.1 & 5.2 & 5.2 & 0.5 & 0.7 & 0.7 & 422 \\
\hline
\end{tabular}

Categories illustrating the majority of responses are bolded.

Table 4. Impact of education level on information need.

\begin{tabular}{|c|c|c|c|c|c|}
\hline Information needs & $\begin{array}{l}\text { High sc } \\
\text { Respondents } \\
\mathbf{n}=\end{array}$ & $\begin{array}{l}\text { 100l or below } \\
\% \text { Think important }\end{array}$ & $\begin{array}{l}\text { Post-sec } \\
\text { Respondents } \\
\mathbf{n}=\end{array}$ & $\begin{array}{l}\text { ary education } \\
\% \text { Think important }\end{array}$ & $\mathbf{P}$ \\
\hline The usual symptoms and how to manage them & 49 & 100 & 332 & 99 & 0.44 \\
\hline The causes of the symptoms & 50 & 100 & 328 & 99 & 0.43 \\
\hline The possible health outcomes in the future & 50 & 100 & 329 & 99 & 0.43 \\
\hline When can I go back to normal activities & 46 & 100 & 318 & 98 & 0.31 \\
\hline Things that I should avoid & 49 & 100 & 323 & 99 & 0.43 \\
\hline Types of available treatments & 49 & 100 & 334 & 99 & 0.39 \\
\hline Who can help me with my condition & 49 & 100 & 321 & 99 & 0.50 \\
\hline
\end{tabular}


Table 5. Importance of specific categories of information after diagnosis.

\begin{tabular}{|c|c|c|c|c|c|c|c|c|}
\hline Categories of information & $\begin{array}{c}\text { Very } \\
\text { important } \\
(\%)\end{array}$ & $\begin{array}{c}\text { Important } \\
(\%)\end{array}$ & $\begin{array}{c}\text { Somewhat } \\
\text { important } \\
(\%)\end{array}$ & $\begin{array}{c}\text { Neutral } \\
(\%)\end{array}$ & $\begin{array}{c}\text { Somewhat } \\
\text { unimportant } \\
(\%)\end{array}$ & $\begin{array}{l}\text { Unimportant } \\
\qquad \%)\end{array}$ & $\begin{array}{c}\text { Very } \\
\text { unimportan } \\
(\%)\end{array}$ & $\begin{array}{l}\text { Total } \\
\text { it } \\
\text { Respondents }\end{array}$ \\
\hline Treatment options & 82.7 & 13.5 & 1.9 & 0.9 & 0.2 & 0.2 & 0.2 & 426 \\
\hline Impacts on my daily life & 81.9 & 14.6 & 1.4 & 1.4 & 0.5 & 0 & 0.2 & 426 \\
\hline How to cope with fibromyalgia & 79.3 & 16.2 & 3.3 & 0.7 & 0.2 & 0.0 & 0.2 & 426 \\
\hline Impact on my ability to work & 78.4 & 14.8 & 2.6 & 2.1 & 0.9 & 0.2 & 0.9 & 426 \\
\hline Changes in my health & 71.5 & 24.1 & 3.3 & 0.9 & 0 & 0 & 0.2 & 424 \\
\hline Exercises that can help with my pain & 67.7 & 22.4 & 6.1 & 2.4 & 0.5 & 0.5 & 0.5 & 424 \\
\hline Emotional impacts & 67.5 & 22.7 & 7.3 & 1.7 & 0.2 & 0.0 & 0.2 & 422 \\
\hline Type of supports exists for people like me & 64.5 & 22.5 & 8.5 & 2.8 & 0.9 & 0.2 & 0.5 & 422 \\
\hline Alternative therapies & 64.3 & 22.8 & 8.0 & 3.1 & 0.5 & 0.2 & 1.2 & 426 \\
\hline Medications that are good for me & 64.2 & 25.0 & 5.9 & 2.8 & 0.9 & 0.2 & 0.9 & 425 \\
\hline Foods that are suitable for me & 61.3 & 22.3 & 9.5 & 4.5 & 1.2 & 0.7 & 0.5 & 421 \\
\hline Connect with people with fibromyalgia & 39.4 & 24.3 & 19.6 & 11.3 & 3.5 & 0.9 & 0.9 & 424 \\
\hline
\end{tabular}

Categories exploring the most endorsed responses are bolded.

Table 6. Impact of gender on information needs.

\begin{tabular}{|c|c|c|c|c|c|}
\hline \multirow{2}{*}{$\begin{array}{l}\text { Information Need } \\
\text { Changes in my health }\end{array}$} & $\begin{array}{l}\text { Fe } \\
\text { Respondents } \\
\mathbf{n}=\end{array}$ & \% Think important & \multicolumn{2}{|c|}{$\begin{array}{l}\text { Male } \\
\text { Respondents \% Think important } \\
\mathbf{n}=\end{array}$} & $\mathbf{P}$ \\
\hline & 362 & 100 & 26 & 100 & 0.79 \\
\hline The impacts of the disease on my daily life & 363 & 99 & 25 & 100 & 0.71 \\
\hline Impact of fibromyalgia on my ability to work & 359 & 98 & 26 & 100 & 0.51 \\
\hline Treatment options & 364 & 100 & 26 & 100 & 0.79 \\
\hline Alternative therapies & 357 & $y$ & 25 & 96 & 0.49 \\
\hline Medications that are good for me & 357 & $99>-2$ & 25 & 96 & 0.31 \\
\hline Exercises that can help with my pain & 360 & 99 & 24 & 100 & 0.60 \\
\hline Foods that are suitable for me & 348 & 98 & 26 & 100 & 0.43 \\
\hline How to connect with people with similar health problems & 326 & 94 & 22 & 100 & 0.24 \\
\hline How to cope with fibromyalgia & $365-2$ & 99 & 27 & 100 & 0.70 \\
\hline Emotional impacts & 356 & 99 & 27 & 100 & 0.63 \\
\hline The type of supports that exist for people like me & 353 & 98 & 26 & 100 & 0.50 \\
\hline
\end{tabular}

Table 7. Frequency of use of information sources.

\begin{tabular}{|c|c|c|c|c|c|c|}
\hline Information sources & $\begin{array}{l}\text { Very } \\
\text { frequently } \\
(\%)\end{array}$ & $\begin{array}{l}\text { Frequently } \\
\qquad(\%)\end{array}$ & $\begin{array}{c}\text { Occasionally } \\
(\%)\end{array}$ & $\begin{array}{l}\text { Rarely } \\
(\%)\end{array}$ & $\begin{array}{l}\text { Never } \\
(\%)\end{array}$ & $\begin{array}{c}\text { Total } \\
\text { Respondents }\end{array}$ \\
\hline Online/Websites & 48 & 30 & 19 & 2 & 1 & 379 \\
\hline Support Groups & 21 & 26 & 28 & 11 & 14 & 331 \\
\hline People with same condition & 17 & 27 & 38 & 10 & 8 & 345 \\
\hline Doctor $(s)$ & 13 & 26 & 36 & 20 & 6 & 362 \\
\hline Other healthcare providers & 9 & 17 & 34 & 12 & 27 & 292 \\
\hline Library & 7 & 14 & 36 & 14 & 29 & 292 \\
\hline Health Magazines & 6 & 18 & 37 & 21 & 17 & 303 \\
\hline Scientific studies & 6 & 16 & 42 & 21 & 16 & 317 \\
\hline Family/Friends & 5 & 14 & 36 & 19 & 25 & 295 \\
\hline Physiotherapists & 4 & 8 & 27 & 24 & 37 & 284 \\
\hline Psychiatrists & 3 & 10 & 16 & 16 & 55 & 268 \\
\hline Other magazines & 3 & 6 & 27 & 24 & 40 & 267 \\
\hline Nurses & 3 & 5 & 11 & 22 & 59 & 257 \\
\hline Rheumatologists & 2 & 9 & 18 & 45 & 26 & 317 \\
\hline Dieticians/Nutritionists & 2 & 7 & 16 & 18 & 57 & 257 \\
\hline TV/Radio & 2 & 6 & 30 & 28 & 34 & 278 \\
\hline Acupuncturists & 1 & 8 & 21 & 25 & 45 & 274 \\
\hline Occupational therapists & 1 & 1 & 11 & 19 & 68 & 247 \\
\hline
\end{tabular}

Categories illustrating the majority of responses are bolded. 
Respondents indicated substantial variability in how useful they perceived different information sources to be. The most useful information sources were websites (48\%), people with same condition (35\%) and support groups (35\%). Only $29 \%$ felt doctors were useful to some extent to access fibromyalgia information. Other clinicians including those who would be expected to spend considerable time promoting self-management (dieticians/nutritionists, nurses, occupational therapists, psychiatrists and rheumatologists) were also commonly seen as not being useful sources (Table 8). In contrast, respondents indicated a preference for receiving information from healthcare providers (Table 9 ) with $52 \%$ wanting information from healthcare providers and
$45 \%$ preferring information from the web. In general, there were few information sources that were not looked upon favorably. About 35\% preferred not to receive fibromyalgia information from face-to-face discussion with their religious leaders. However, the majority (93\%) of the respondents preferred to use online information that was provided by healthcare professionals or by reputable sources.

Respondents reported their use of information as represented in Figure 1. While responses varied, there was a strong endorsement of the need for information with only $1 \%$ of the respondents reporting they did not use information at all to understand their disease. Some (12\%) of the respondents provided openended responses regarding the barriers to use

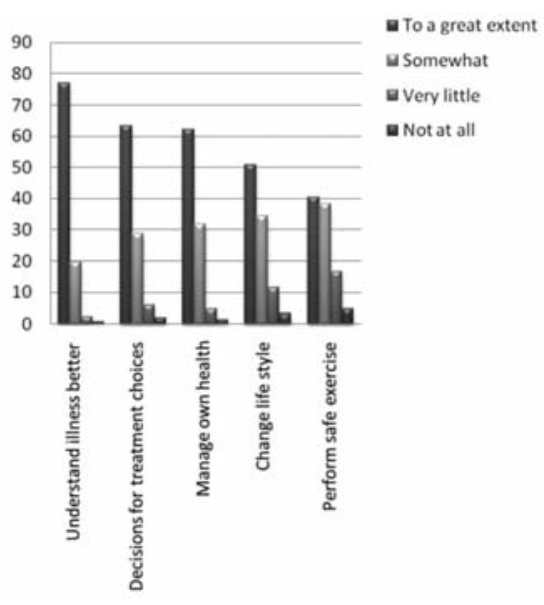

Figure 1. Frequency of use of information.

Table 8. Usefulness of different information sources.

\begin{tabular}{|c|c|c|c|c|c|c|c|c|c|}
\hline & $\begin{array}{l}\text { Information } \\
\text { sources } \\
\%\end{array}$ & $\begin{array}{l}\text { Very } \\
\text { useful } \\
\%\end{array}$ & Useful & $\begin{array}{l}\text { Somewhat } \\
\text { useful } \\
\%\end{array}$ & $\begin{array}{l}\text { Neutral } \\
\qquad \%\end{array}$ & $\begin{array}{c}\text { Somewhat } \\
\text { unuseful } \\
\%\end{array}$ & $\begin{array}{c}\text { Unuseful } \\
\%\end{array}$ & $\begin{array}{c}\text { Not useful } \\
\text { at all } \\
\%\end{array}$ & $\begin{array}{c}\text { Total } \\
\text { respondents } \\
\%\end{array}$ \\
\hline Most useful & $\begin{array}{l}\text { Online/Websites } \\
\text { People with same condition } \\
\text { Support groups }\end{array}$ & $\begin{array}{l}48 \\
35 \\
35\end{array}$ & $\begin{array}{l}33 \\
27 \\
21\end{array}$ & $\begin{array}{l}15 \\
20 \\
18\end{array}$ & $\begin{array}{c}3 \\
8 \\
13\end{array}$ & $\begin{array}{l}1 \\
3 \\
3\end{array}$ & $\begin{array}{l}0 \\
1 \\
2\end{array}$ & $\begin{array}{l}1 \\
6 \\
9\end{array}$ & $\begin{array}{l}398 \\
370 \\
378\end{array}$ \\
\hline Somewhat useful & $\begin{array}{l}\text { Doctor (s) } \\
\text { Health Magazines } \\
\text { Family/Friends } \\
\text { Scientific studies }\end{array}$ & $\begin{array}{c}17 \\
9 \\
8 \\
20\end{array}$ & $\begin{array}{l}18 \\
20 \\
11 \\
22\end{array}$ & $\begin{array}{l}29 \\
27 \\
26 \\
24\end{array}$ & $\begin{array}{l}8 \\
21 \\
24 \\
19\end{array}$ & $\begin{array}{l}8 \\
3 \\
7 \\
3\end{array}$ & $\begin{array}{l}7 \\
4 \\
9 \\
3\end{array}$ & $\begin{array}{l}14 \\
16 \\
16 \\
10\end{array}$ & $\begin{array}{l}402 \\
368 \\
360 \\
358\end{array}$ \\
\hline Not useful & $\begin{array}{l}\text { Nurses } \\
\text { Occupational Therapists } \\
\text { Psychiatrists } \\
\text { Dieticians/Nutritionists } \\
\text { Acupuncturists } \\
\text { Other Magazines } \\
\text { TV/Radio } \\
\text { Physiotherapists } \\
\text { Rheumatologists } \\
\text { Other healthcare providers } \\
\text { Library }\end{array}$ & $\begin{array}{c}4 \\
4 \\
5 \\
5 \\
8 \\
4 \\
3 \\
8 \\
10 \\
14 \\
10\end{array}$ & $\begin{array}{c}3 \\
4 \\
9 \\
8 \\
8 \\
8 \\
9 \\
13 \\
12 \\
12 \\
20 \\
\end{array}$ & $\begin{array}{l}9 \\
9 \\
13 \\
13 \\
15 \\
18 \\
20 \\
16 \\
19 \\
21 \\
19\end{array}$ & $\begin{array}{l}35 \\
39 \\
29 \\
35 \\
30 \\
33 \\
32 \\
28 \\
20 \\
25 \\
24\end{array}$ & $\begin{array}{l}4 \\
4 \\
4 \\
2 \\
6 \\
5 \\
5 \\
6 \\
8 \\
4 \\
4\end{array}$ & $\begin{array}{l}10 \\
6 \\
8 \\
7 \\
6 \\
6 \\
5 \\
6 \\
8 \\
4 \\
3\end{array}$ & $\begin{array}{l}35 \\
34 \\
33 \\
31 \\
28 \\
27 \\
26 \\
23 \\
22 \\
21 \\
20\end{array}$ & $\begin{array}{l}355 \\
343 \\
353 \\
345 \\
347 \\
345 \\
350 \\
360 \\
380 \\
364 \\
353\end{array}$ \\
\hline
\end{tabular}

Categories illustrating the majority of responses are bolded.

Table 9. Preferred format of information sources.

\begin{tabular}{|c|c|c|c|c|c|c|c|c|}
\hline Format of information sources & $\begin{array}{c}\text { Strongly } \\
\text { prefer } \\
\%\end{array}$ & $\begin{array}{c}\text { Prefer } \\
\%\end{array}$ & $\begin{array}{c}\text { Somewhat } \\
\text { prefer } \\
\%\end{array}$ & $\begin{array}{c}\text { Neutral } \\
\%\end{array}$ & $\begin{array}{c}\text { Somewhat } \\
\text { dislike } \\
\%\end{array}$ & $\begin{array}{c}\text { Dislike } \\
\%\end{array}$ & $\begin{array}{c}\text { Strongly } \\
\text { dislike } \\
\%\end{array}$ & $\begin{array}{l}\text { Total } \\
\text { respondents }\end{array}$ \\
\hline Face-to-face with healthcare providers & 52 & 27 & 11 & 7 & 1 & 1 & 1 & 400 \\
\hline Online/Websites & 45 & 35 & 17 & 3 & 0 & 0 & 0 & 399 \\
\hline Face-to-face with a person with fibromyalgia & 36 & 27 & 19 & 15 & 2 & 1 & 1 & 400 \\
\hline Books & 37 & 34 & 17 & 12 & 0 & 1 & 1 & 392 \\
\hline Email & 33 & 33 & 20 & 10 & 1 & 1 & 2 & 393 \\
\hline Newsletters & 29 & 32 & 21 & 13 & 3 & 1 & 1 & 392 \\
\hline Face-to-face with support groups & 28 & 24 & 18 & 17 & 7 & 2 & 4 & 395 \\
\hline Videos (CD/DVD) & 18 & 21 & 21 & 26 & 6 & 3 & 5 & 385 \\
\hline Magazines & 18 & 25 & 24 & 25 & 3 & 2 & 3 & 386 \\
\hline Pamphlets /Brochures & 13 & 23 & 30 & 24 & 5 & 2 & 2 & 394 \\
\hline Audios & 11 & 14 & 18 & 35 & 8 & 7 & 8 & 368 \\
\hline Telephone & 10 & 11 & 12 & 29 & 12 & 9 & 18 & 381 \\
\hline Face-to-face with religious leaders & 4 & 4 & 8 & 34 & 6 & 9 & 35 & 385 \\
\hline
\end{tabular}

Categories illustrating the majority of responses are bolded. 
of information. They specifically mentioned about a lack of useful information (20\%), and lack of access to care (8\%) and the remainder discussed about the use of information for family/friends, to manage emotional impacts, and to help educate doctors about fibromyalgia. Finally, a substantial number of respondents (54\%) provided spontaneous open-ended responses to the last question of the survey where participants were asked to share additional information regarding their information needs and preferences. They reported their frustration with healthcare providers (12\%); the need for more education for physicians (15\%); better availability of information for families (5\%); coping strategies (12\%); more information about fibromyalgia (12\%); their struggle with unemployment insurance $(2 \%)$; the need for awareness among government (10\%), and the public (4\%); concerns about the reliability of information (5\%) and rest discussed about lack of access to treatment information that is available in other countries; funding for fibromyalgia research; specific treatment such as Guaifenesin Protocol; and struggles with physical and mental suffering for living with fibromyalgia.

\section{Discussion}

The survey results revealed that people living with fibromyalgia are active searchers and users of information and that they have broad information needs. They have continuous need for information that can help them understand their disease condition and its prognosis, treatment options, and coping strategies. Peopleuse information to make informed healthcare decisions and gain support from healthcare providers and others. Previous studies of people living with fibromyalgia or other chronic illnesses have also indicated strong need for condition specific information. $5,10,19,20,34,38,39$ This study builds on those findings by focusing on the specific types of information need and the sources that are used to locate it. Our findings suggest that there is a substantial gap between information needs and what people are able to access. About three out of five respondents strongly agree that due to a lack of information and support from healthcare providers, they frequently search for information about their illness from a variety of sources. It is also important to note that the need for specific information is equally important both for women and men with different levels of education. However, we acknowledge that our sample was preliminary female and well educated so the possibility for us to miss this effect is considerable.

Information needs do vary based on stage of the disease. For example, on one hand, people indicate that it is important to them to know more about symptoms and future consequences of the disease before the final diagnosis with fibromyalgia. On the other hand, it is important to know more about treatments, impacts on life, coping, and alternative supports after they are diagnosed with fibromyalgia. This is a new finding and might suggest that information should be organized according to whether people are in the process of being diagnosed with fibromyalgia or have a confirmed diagnosis.

One of the other key findings of this study is that although people express a strong desire to seek information from their health care providers, their experiences have been unsatisfactory. A minority of respondents indicated that healthcare professionals are very helpful in terms of providing useful information. of equal concern, up to one third of healthcare providers who spend considerable time with people and often use education for behavior modification (dietitians, occupational therapists, and psychiatrists) are perceived as inadequate sources. Conversely, the sources seen as most useful are the Internet, other people who are living with fibromyalgia and support groups. These findings are consistent with other studies that investigated the patterns of Internet use and health information seeking behavior of people with chronic illnesses (cancer, heart problems, diabetes, back pain and fibromyalgia)..$^{10,40}$ Berger and colleagues studied the associations between chronic illness and frequency of Internet use for - health information, communication with healthcare providers, changes in health care utilization, and satisfaction with the Internet. ${ }^{40}$ Their findings suggested that people with chronic illnesses are more likely to use the Internet for health information, to improve communication with healthcare providers and to increase the use of health care based on information found on the Internet.40 The authors also recommended the Internet as a valuable tool for health communication and education for people living with chronic illnesses.

Another new finding from our study is that many people living with fibromyalgia do not want to receive information about their health from religious leaders. This suggests that strategies that may use religious leaders to disseminate health knowledge or transfer this knowledge into practice should be approached with caution.

Self-management is achieved when healthcare providers confirm that persons with chronic illness have the confidence and skills to manage their condition; the most appropriate treatments to assure optimal disease control and prevention of complications; a mutually understood care plan; and careful, continuous follow-u $p^{27}$ Given these principles of self-man- agement with chronic conditions, there is a central gap between the theoretical foundations of self-management and people's experiences with acquiring the information they need to self manage. ${ }^{27}$ Our data call into question whether chronic management strategies are being effectively implemented by clinicians when a substantial proportion of patients believe that they have not been provided with adequate information. However, it is notable that despite ranking the healthcare providers as low on being useful information sources, people prefer to receive information in-person from them. This suggests that there is a need for healthcare providers to play a vital role in providing valuable information to their patients and develop a more patient-centered interaction in order to empower people with fibromyalgia. Wagner and colleagues also advocate this notion; High-quality chronic illness care is characterized by productiveinteractions between practice team and patients. ${ }^{27}$ Further studies are needed to develop knowledge exchange strategies and transfer tools that could facilitate better communication between healthcare providers and people living with fibromyalgia. More efforts are needed to develop easily accessible information sources in a format preferred by this group of people.

Our data do suggest that the concept of selfmanagement ${ }^{27}$ has value since people report that they use information largely to improve their knowledge of the disease and self-manage their health. However, this study was unable to test the effect of information on health outcomes or quality of life. The relationship between information use and health outcomes for people living with fibromyalgia has yet to be determined. Further research is needed to examine to what extent health information generates measurable health and quality of life outcomes for them.

Although we are unable to determine whether concerns about information quality contribute to differences between changing knowledge and behavior, the data do indicate that respondents have a substantial apprehension about the quality of information they are able to access. Concerns about the quality of information have also been reported by many researchers. For example, a study was conducted to evaluate the nature and quality of kidney transplant-related information available on the Internet and found that the information was of poor quality in terms of source, language, accessibility and quality/depth. ${ }^{41}$ People with other chronic conditions (social phobia, paediatrics neuro-oncology, depression, cancer) similarly expressed their frustration resulting from barriers to accessing reliable information. ${ }^{42-46}$ These findings suggest that if people do not have confidence in information- they might be less likely to act upon it. Therefore, 
regardless of whether the information is or is not accurate, it is important to establish a variety of approaches that might be needed to ensure that people living with fibromyalgia are able to identify and access high-quality information and acquire the confidence they need to act upon that information. Self-management programs may need to enhance participants' skills in communicating with their healthcare providers, their ability to access high quality information sources, skills in assessing information quality, and specific strategies to deal with situations where they have not been provided with adequate information.

\section{Implications for practice}

This study has implications for people living with fibromyalgia and all those who attempt to empower them through the use of information including families, caregivers, resource developers, librarians, nonprofit agencies/support groups and clinicians. People living with fibromyalgia need adequate and accessible knowledge that supports their needs during both diagnosis and the subsequent living with chronic disease stages. Given the mismatch between people's preferences for attaining knowledge through healthcare providers and the extent to which this is currently operationalized, there is a need for enhanced communication between clinicians, care providers and people with fibromyalgia around their information needs. However, persons with fibromyalgia could play more active role as knowledge brokers to improve this communication as they have gained ample knowledge to be trained as knowledge brokers through selfmanagement.

Healthcare providers may need additional training to take on the role as knowledge brokers as well for patients with fibromyalgia. In addition, awareness of how to teach patients generic skills assessing the quality of health information and specific tools/information sources for fibromyalgia would enhance clinicians' roles as knowledge brokers. At a minimum clinicians should be able to recommend generic and disease specific high-quality health information, assess their patients' ability to access and use information and have ongoing communication with their patients to understand their knowledge and information needs. These skills, while not a traditional focus in clinical training may be particularly important for the management of chronic diseases. In addition, it would be important when evaluating clinicians' skills in chronic disease management that the important aspect of empowering people to use health information optimally should be specifically evaluated and opportunities for skill enhancement provided if needed.

Similarly, the extent to which patients use the Internet suggests a role for health librarians to facilitate people living in the community with fibromyalgia to access appropriate information sources. Health librarians might also develop sources to assist with improving chronic disease programs for hospital-based education programs. The sources may empower patients with fibromyalgia to access highquality web information and communicate their information needs.

Patient support groups might also act as important knowledge brokers between clinicians and people living with fibromyalgia. Since such groups tend to be nonprofit organizations and organized by lay people living with the disease, one potential vehicle for improving both the process and content of information access and use would be through targeted training of leaders and information resource developers within these organizations. These groups might also serve as a vehicle for training patients on how to more effectively interact with healthcare providers to discuss issues around information access, validity, personal relevance and usability.

\section{Study limitations}

There are limitations to our study, some arise from the nature of the web-based survey and others are inherent to the population or to our sample. The majority of the respondents are female, which is consistent with the epidemiology of the disease, but resulted in a lack of power to differentiate gender differences. We also have a high prevalence of respondents who are highly educated. This sampling may have arisen given that educated (and likely more economically advantaged) individuals are more likely to have home computers or time to dedicate to the survey. This type of respondent may also be more likely to have repeat interactions with their healthcare provider and join social support groups. For this reason, people who are less well educated or more socially isolated may not have been adequately represented in our sample. It is possible that these groups have particular information needs. One way to address this problem may be to use sampling strategies that specifically recruit isolated or disenfranchised subgroups of the fibromyalgia population and use qualitative methods to address this potential gap in the future. Since the majority of the respondents are Caucasian the study results may not reflect the experience of people from different ethnic backgrounds or cultural contexts who are living with fibromyalgia. This study serves as a foundation for understanding the knowledge behaviours and needs of people living with fibromyalgia and indicates a need for future studies that focus on differential needs related to personal, environmental and disease factors.

\section{References}

1. Rodham K, Rance N, Blake D. A qualitative exploration of carers' and 'patients' experiences of fibromyalgia: one illness, different perspectives. Musculos Care 2010;86877.

2. Neumann L, Buskila D. Epidemiology of fibromyalgia. Current Pain Headache Repor 2003;7:362-8.

3. Schaefer KM. The Lived Experience of Fibromyalgia in African American Women. Holis Nurs Practice 2005;19:17-25.

4. Schmidt A, Husberg M, Bernfordt L. Social costs for rheumatology diseases. Linkoping University Centre for Medical Technology Assessment (CMT). Report; no $5,2003$.

5. McNally JD, Matheson DA, Bakowsky VS. The epidemiology of self-reported fibromyalgia in Canada. Chro Disea Canada 2006;27:9-16.

6. White KP, Speechley M, Harth M, Ostbye T. The Lodon fibromyalgia epidemiology study: the prevalence of fibromyalgia syndrome in London, Ontario. J Rheumatol 1999;26:1570-6.

7. Weir PT, Harlan GA, Nkoy FL, et al. The incidence of fibromyalgia and its associated comorbidities: a population-based retrospective cohort study based on international classification of diseases, 9th revision codes. J Clinic Rheum 2006;12:124-8.

8. Bennett MR. Clinical Manifestations and Diagnosis of Fibromyalgia. Rheum Dis Clin North Am 2009;35:215-32.

9. Bennett MR, Jones J, Turk CD, et al. An internet survey of 2,596 people with fibromyalgia. BMC Musculosk Dis 2007;8: 27.

10. Crooks VA. I go on the Internet; I always, you know, check to see what's new" chronically ill women's use of online health information to shape and inform doctorpatient interactions in the space of care provision. ACME: An Intern E-Journal for Crit Geograp 2006;5:50-69.

11. Arnold LM, Crofford LJ, Mease PJ, et al. Patient perspectives on the impact of fibromyalgia. Patient Educ Couns 2008;73:114-20.

12. Gunilla M, Liedberg, Cris M. Henriksson. Factors of Importance for work disability in women with fibromyalgia: an interview study. Arthritis Care Res 2002;47:266-74.

13. Henriksson CM. Long-term effects of fibromyalgia on every-day life: a study of 56 patients. Scand J Rheumatol 1994;3:3541.

14. Furlong LV, Zautra A, Puente CP, et al. Cognitive-affective assets and vulnerabilities: two factors influencing adaptation to fibromyalgia. Psychol Health 2010;25:197- 
212.

15. Kennedy M, Felson DT. A prospective longterm study of fibromyalgia syndrome. Arthritis Rheum 1996;39:682-5.

16. Kool MB, Middendorp HV, Boeije HR, Geenen R. Understanding the lack of understanding: invalidation from the perspective of thepatient with fibromyalgia. Arthr Rheumat 2009;61:1650-6.

17. Rheumatology.org [Internet]. Atlanta: American College of Rheumatology. http://www.rheumatology.org/ Accessed: 2011 Feb 18.

18. Pongratz D, Sievers M. Fibromyalgia symptom or diagnosis: A definition of the position. Scand J Rheumatol Suppl 2000; 113:3-7.

19. Lofgren M, Ekholm J, Ohman A. 'A constant struggle': Successful strategies of women in work despite fibromyalgia. Disab Rehab 2006;28:447-55.

20. Sallinen M, Kukkurainen ML, Peltokallio L, Mikkelsson M. Women's narratives on experiences of work ability and functioning in fibromyalgia. Musculosk Care 2010;8:18-26.

21. Soderberg S, Lundman B, Norberg A. Living with fibromyalgia: sense of coherence, perception of well-being and stress in daily life. Res Nurs Health 1997;20:495503.

22. Jain AK, Carruthers BM. Canadian clinical working case definition, diagnostic and treatment protocols- a consensus document. J Musculosk Pain 2003;11:3107.

23. White LA, Birnbaum HG, Kaltenboeck A, et al. Employees with fibromyalgia: Medical comorbidity, healthcare costs, and work loss. J Occup Env Med 2008;50:13-24.

24. Paulson M, Norberg A, Danielson E. Men living with fibromyalgia-type pain: experiences as patients in the Swedish health care system. J Adv Nurs 2002; 40:87-95.

25. Sim J, Madden S. Illness experience in fibromyalgia syndrome: a metasynthesis of qualitative studies. Soc Sc Medic 2008;67:57-67.

26. Koulil SV, Kraaimaat FW, Lankveld WV, et al. A patient's perspective on multidisciplinary treatment gain for fibromyalgia: An indicator for pre-post treatment effects? Arthr Rheumatol 2009;61:1626-32.

27. Wagner EH, Austin BT, Davis C, et al. Improving chronic illness care: Translating evidence into action interventions that encourage people to acquire self-management skills are essential in chronic illness care. Heal Affair 2001;20:64-78.

28. Davison NS. End-of-Life Care Preferences and Needs: Perceptions of Patients with Chronic Kidney Disease. Clin J Am Soc Nephrol 2010;5:195-204.

29. Madden S, Sim J. Creating meaning in fibromyalgia syndrome. Soc Sci Med 2006; 63:2962-73.

30. Cunningham MM, Jillings C. Individuals' descriptions of living with fibromyalgia. Clin Nurs Res 2006;15:258-73.

31. Lempp HK, Hatch SL, Carville S F, Choy EC. Patients' experiences of living with and receiving treatment for fibromyalgia syndrome: a qualitative study. BMC Musculos Dis 2009;10:124.

32. Warner D, Procaccino DJ. Toward wellness: women seeking health information. J Am Soc Inform Sci Tech 2004;55:709-73.

33. Halpert A, Dalton CB, Palsson 0, et al. Drossman Irritable Bowel Syndrome Patients' Ideal Expectations and Recent Experiences with Healthcare Providers: A National Survey. Dig Dis Sci 2010;55:37583.

34. Daraz L. Information needs and availability of people with Fibromyalgia [dissertation]. Chapter 2. Hamilton, ON, Canada: McMaster University; 2011.

35. Raymond MC, Brown JB. Experience of fibromyalgia. Qualitative study. Canad Family Phys 2000;46:1100-6.
36. Couper MP, Traught MW, Lamias MJ. Web survey design and administration. Public Opin Quart 2001;65:230-53.

37. Andrews D, Nonnecke B, Preece J. Electronic survey methodology: a case study in reaching hard-to-involve internet users. Intern J Human-Comp Inter 2003;16:185-210.

38. Hogan PT, Palmer LC. Finding and using medical information. "Information work" and chronic illness: interpreting results from a nationwide survey of people living with HIV/AIDS. Proceed Am Soc Info Sci Tech 2005;42.

39. Arthritis.ca. [Internet]. Toronto: The Arthritis Society. http://www.arthritis.ca Accessed: 2011 Jan 30.

40. Berger M, Wagner TH, Baker LC. Internet use and stigmatized illness. Soc Sci Med 2005;61:1821-7.

41. Hanif F, Abayasekara K, Willcocks L, et al. The quality of information about kidney transplantation on the World Wide Web. Clin Transplant 2007;21:371-6.

42. Khazaal Y, Fernandez MA, Cochand S, et al. Quality of web-based information on social phobia: a cross-sectional study. Depress Anxiety 2008;25:461-5.

43. Hargrave DR, Hargrave UA, Bouffet E. Quality of health information on the Internet in pediatric neuro-oncology. Neuro Oncol 2006;8:175-82.

44. Griffiths KM, Christensen H. The quality and accessibility of Australian depression sites on the World Wide Web. Med J Aus 2002;176:97-104.

45. Al-Bahrani A, Plusa S. The quality of patient-oriented internet information on colorectal cancer. Color Dis 2004;6:323-6.

46. Graydon, J, Galloway S, Palmer-Wickham $\mathrm{S}$, et al. Information needs of women during early treatment for breast cancer, J Advan Nurs 1997;26:59-64. 